\title{
Özel Eğitim Alanında Çalışan Öğretmenlerin Özel Eğitimde Yardımcı Teknolojilerin Kullanımına İlişkin Görüşleri*
}

\section{Metehan KUTLU**, Sinan SCHREGLMANN*** , Nail Anıl CÍNISLI*****}

Öz: Bu araştırmanın amacı özel eğitim alanında çalışan öğretmenlerin özel eğitimde yardımcı teknolojilerin kullanımına ilişkin görüş ve düşüncelerini belirlemektir. Bu araştırma tarama modelinde betimsel bir çalışmadır. Araştırmanın çalışma grubunu özel eğitim alanında çalışan 211 öğretmen oluşturmaktadır. Araştırmada veri toplama aracı olarak Chmiliar (2007) tarafından geliştirilen anket kullanılmıştır. Veri analiz sürecinde frekans, yüzde, aritmetik ortalama ve standart sapma hesaplamalarına yer verilmiştir. Araştırmanın verileri yaş, cinsiyet, mevcut görev, öğretim kademesi, mesleki kıdem, eğitime alma durumu, bilgi ve beceri düzeyi, memnuniyet, yardımcı teknoloji kullanma sıklığı, bütçe durumu, yardımcı teknolojiye erişebilen öğrenci sayısı, yardımcı teknoloji kullanımına engel oluşturan faktörler ve destek stratejileri açısından analiz edilmiştir. Araştırma sonucunda öğretmenleri özel eğitimde yardımcı teknolojilerin kullanımı konusunda en çok engelleyen faktörlerin araç-gereçlerin maliyeti ve karmaşıklığı, okullarda öğrenciler için yeterli yardımcı teknoloji araç-gereçlerinin bulunmaması ve yardımcı teknolojilerle ilgili bilgi eksikliği olduğu belirlenmiştir. Yardımcı teknolojilerin kullanımına ilişkin en önemli destek stratejileriyle ilgili faktörlerin ise araç-

*Bu çalışma Hakkari Üniversitesi Bilimsel Araştırma Projeleri Komisyonu Tarafından Desteklenmiştir. Proje Numarası: SB18BAP8. Bu çalışma 5. Uluslararası Multidisipliner Çalışmaları Kongresinde Sözlü Bildiri Olarak Sunulmuştur.

** Dr. Öğr. Üyesi, Hakkari Üniversitesi Eğitim Fakültesi, Özel Eğitim Bölümü, Türkiye. ORCID ID: 0000-0003-4468-6094, Email: metkutlu@gmail.com

*** Dr. Öğr. Üyesi, Hatay Mustafa Kemal Üniversitesi Eğitim Fakültesi, Eğitim Bilimleri Bölümü, Türkiye. ORCID ID: 0000-0002-5738-3167, Email:sinansch@gmail.com.

***** Öğr. Gör. Hakkari Üniversitesi Eğitim Fakültesi, Özel Eğitim Bölümü, Türkiye. ORCID ID: 0000-0002-3610-7024, Email: nacinisli@gmail.com

\begin{tabular}{lll}
\hline Gönderim:31.08.2018 & Kabul:10.11.2018 & Yayın:15.12.2018
\end{tabular}


gereçlerin sağlanmasıyla ilgili bütçe desteği, yardımcı teknolojilerle ilgili eğitim desteği ve araç-gereçlerin kullanımında teknik desteğe erişim olduğu belirlenmiştir.

Anahtar Kelimeler: Yardımcı teknolojiler, Özel eğitim, Öğretmenler

\section{The Opinions of Special Education Teachers on the Use of Assistive Technologies in \\ Special Education}

Abstract: This research is a descriptive study aiming to determine at what level assistive technologies are utilized in the special education field, to identify the barriers to use of assistive technologies, and to support strategies based on opinions and thoughts of teachers working on this field. The population of this research was constituted by teachers working in public and private education institutions operating in 2017-2018 academic year affiliated to the city of Hakkâri in Turkey. In this research, a survey developed by Linda Chmiliar of Athabasca University in 2007 was used as the data collection tool. The study included 211 teachers from different age groups, gender and students with special needs at different levels of instruction. As a result of the research, it was determined that the most restricting factors in the use of assistive technologies in special education were the cost of the equipment, lack of sufficient assistive technology tools for the students and lack of knowledge about the assistive technologies. Factors related to the most important support strategies related to the use of assistive technologies were identified as budget support for providing tools and equipment, educational support for assistive technologies and technical support for the use of equipment.

Keywords: Assistive technology, Special education, Teachers 


\section{Giriş}

Özel eğitimin temel amacı özel gereksinimli bireylerin toplumda bağımsız birer birey olarak yaşayabilmeleri ve normal gelişim gösteren bireylerle en az kısıtlayıcı eğitim ortamlarında eğitimlerini sürdürmesi esasına dayanmaktadır. En az kısıtlayıcı eğitim ortamı özel gereksinimli bireylerin genel eğitim müfredatlarından yararlanması ve akranlarılla birlikte genel eğitim sınıflarında kaynaştırma ya da diğer bir ifadeyle bütünleştirme uygulamaları kapsamında eğitim-öğretim sürecinin bir parçası olmalarını ifade etmektedir (Alper ve Raharinirina, 2006; Sani-Bozkurt, 2017). Özel gereksinimli bireylerin genel eğitim müfredatından etkin bir şekilde yararlanabilmesi için okul ortamında bir takım öğretimsel uyarlamaların yapilması gerekmektedir (Alquraini ve Gut 2012; Carey ve Sale 1994). Öğretimsel uyarlamaların başında ise yardımcı teknolojiler gelmektedir (Coleman, Cramer, Park ve Bell, 2015). Yardımcı teknolojiler, özel gereksinimli bireylerin eğitim hizmetlerinden yararlanmasını sağlamak, toplumda bağımsız birer birey olarak yaşamlarını sürdürmek ve yaşam kalitelerini artırmak için kullanılan her türlü araç, hizmet veya yöntemler olarak tanımlanabilir (Johnston, Thurlow, Altman, Timmons, ve Kato, 2009; Reed ve Bowser, 2005). Örneğin, otizmli bir öğrencinin sınıf içi etkinliklerin ne zaman ve nasıl yapılacağını öğrenebilmesi için resimli ya da yazılı günlük planlar hazırlanabilir. Resimli günlük planlar otizmli öğrencinin sınıf ortamında gerçekleştirilecek etkinlikleri daha iyi algılamasını ve sınıfa daha iyi uyum sağlayabilmesine hizmet edebilir. Verilen örnekte otizmli öğrenci için kullanılan görsel plan aslında bir tür yardımcı teknolojidir. Yardımcı teknolojiler özel gereksinimli öğrencilerin çeşitli becerileri öğrenmelerinin yanı sıra, kendilerine olan güvenini, yaşam kalitelerini ve en önemlisi toplumda bağımsı birer birey olarak yaşayabilmelerini etkileyebilmektedir ("Wisconsin Assistive Technology Initiative", 2018). Yardımc1 teknolojiler düşük düzey, orta düzey ve yüksek düzey teknoloji içeren araç-gereçler olmak üzere üç farklı kategoride incelenebilir (Aslan, 2018; Johnston, Beard ve Carpenter, 2007; 
Sani-Bozkurt, 2017). Düşük düzey yardımcı teknoloji araçları arasında okuma sorunu olan bireyler için okuma büyüteçleri, fosforlu işaretleyiciler, görsel kartlar/resimler/semboller, sayfa çevirme aparatı sayılabilir. Orta düzey teknoloji araçları arasında okuma kalemleri, konuşan hesap makinalar, konuşan sözlükler veya denge sorunu olan özel gereksinimli bireyler için özel ortopedik koltuk/sandalye sayılabilir. Yüksek/İleri düzey teknoloji araçları arasında özel gereksinimli bir çocuğun konuşmasını destekleyen bir bilgisayar sistemi, tablet bilgisayar, akıllı telefon olabileceği gibi kalıcı olarak kollarını ve bacaklarını kullanamayan özel gereksinimli bireyin mektup yazabilmesi için geliştirilmiş bir yazılım sistemi de sayılabilir.

Geliştirilen yardımcı teknolojilerin yanı sıra öğretmenlerin yardımcı teknolojileri sınıflarında ne kadar sıklıkla ve ne derece etkili kullandığı da önemlidir (Judge, 2001; Van Netten, Jannink, Hijmans, Geertzen ve Postema, 2010). Yardımc1 teknolojilerin etkili bir şekilde kullanımı, özel eğitim öğretmenlerinin yardımcı teknolojilerle ilgili ne kadar bilgi ve donanıma sahip olduğuyla yakından ilgilidir. Öğretmenlerin yardımcı teknolojilerle ilgili yeterli bilgi ve donanıma sahip olamaması ve buna bağlı olarak yardımcı teknolojileri kullanmada kendilerini yeterli hissetmemeleri yardımcı teknolojilerin kullanımındaki en büyük engellerden biri olarak düşünülmektedir (Copley ve Ziviani, 2004; Hutinger ve diğ., 1994; McGregor ve Pachuski, 1996; Parette, 1997; Parker ve diğ., 1990; Zhou, Parker, Smith ve Griffin-Shirley, 2011). Alanyazında özel eğitim öğretmenlerinin yardımc1 teknolojilerin kullanımı konusundaki görüş ve düşüncelerinin incelendiği yayımlanmış çeşitli araştırmalar bulunmaktadır (Alammary, Al-Haiki ve Al-Muqahwi, 2017; Alper ve Raharinirina, 2006; Chmiliar, 2007; Copley ve Ziviani, 2004; Derer, Polsgrove ve Rieth 1996; Sydeski, 2013). Bu araştırmalardan elde edilen bulgular, öğretmenlerin yardımcı teknolojilerle ilgili eğitim gereksinimlerinin olduğunu, mevcut bilgi ve donanımlarından memnun olmadıklarını ve yardımcı teknoloji araç-gereçlerinin maliyetinin yardımcı teknolojilerin kullanımında önemli birer engel olduğunu düşündüklerini göstermiştir. 
Ulusal alanyazında ise özel eğitim öğretmenlerinin yardımcı teknolojilerin kullanımı konusundaki görüşlerinin/tutumlarının incelendiği yayımlanmış sınırlı sayıda araştırmaya rastlanmıştır (Aslan, 2018; Deniz ve Demirkıran, 2006; Kışla, 2008; Sola-Özgüç ve Cavkaytar, 2014; Tekinarslan ve Y1kmış, 2005). Araştırmalardan elde edilen bulgular yardımcı teknolojilerin özel eğitim sınıflarında çok sınırlı olduğunu ya da hiç kullanılmadığını, yardımcı teknoloji araç gereçlerinin alımı için gerekli bütçenin yeterli olmadığını, teknik desteğe erişim konusunda güçlükler yaşandığını, özel eğitim öğretmenlerinin teknolojiyi kullanmada gerekli bilgi ve donanıma sahip olmadıklarını, yardımcı teknolojilerin kullanımı konusunda kendilerini yetersiz algıladıklarını ve özel eğitim öğretmenlerine yardımcı teknolojilerle ilgili hizmet içi eğitimler düzenlenmesinin önemli olabileceğini göstermektedir. Ulusal alanyazında özel eğitim öğretmenlerinin yardımcı teknolojilerin kullanımıyla ilgili görüş ve düşüncelerinin incelendiği araştırmalardan elde edilen bulguların uluslararası alanyazında var olan bulgularla benzer olduğu söylenebilir.

Ulusal alanyazında özel eğitim öğretmenlerinin yardımcı teknolojilerin kullanımı konusundaki görüşlerini ortaya koyan yayımlanmış bir anket çalışmasının olmamasının bu çalışmanın ulusal alanyazına önemli bir katkı sağlayabileceği düşünülmektedir. Ayrıca ülkemizde görev yapan özel eğitim öğretmenlerinin yardımcı teknolojileri kullanmalarını engelleyen faktörlerin belirlenmesinin ve buna bağlı olarak gerekli düzenlemelerin yapılarak uygulanabilecek destek stratejilerinin sağlanmasının ve eğitim politikalarının geliştirilmesinin önemli olabileceği düşünülmektedir.

Bu çalışma kapsamında Hakkâri İl Milli Eğitim Müdürlüğü’nden Hakkâri il merkezi ve ilçelerinde (Çukurca, Şemdinli, Yüksekova) görev yapan özel eğitim öğretmenlerinin sınıflarında kullandıkları yardımcı teknolojilerle ilgili araç-gereç envanter listeleri istenmiştir. Okulların ve özel eğitim merkezlerinin envanter listelerinde akıllı tahta, masaüstü/dizüstü bilgisayar, resimli kartlar/resimler/fotoğraf, fosforlu işaretleyiciler ve okuma kalemlerinden 
sınırlı sayıda olduğu rapor edilmiştir. Ayrıca alanyazında bugüne kadar Hakkâri ilinde görev yapan özel eğitim öğretmenlerinin sınıflarında bulunan yardımcı teknolojilerin kullanımıyla ilgili görüş ve düşüncelerinin incelendiği herhangi bir araştırmaya rastlanmamıştır. Bu bağlamda bu çalışmada özel eğitim alanında çalışan öğretmenlerin özel eğitimde yardımcı teknolojilerin kullanımına ilişkin görüş ve düşüncelerini incelemek amaçlanmış ve aşağıdaki alt amaçlara yanıt aranmıştır:

1. Özel eğitim alanında çalışan öğretmenlerin demografik bilgileri, (yaş, cinsiyet, branş bazında mevcut görevleri, çalıştıkları öğretim kademesi, mesleki kıdemleri), yardımcı teknolojilerle ilgili hizmet-içi eğitim alma durumları, bilgi ve beceri düzeyleri, bütçe durumu, memnuniyet düzeyleri, yardımcı teknolojileri sınıflarında kullanma sıklıkları ve yardımcı teknolojiye erişebilen öğrenci sayısı nelerdir?

2. Özel eğitim alanında çalışan öğretmenlerin yardımcı teknolojinin kullanımında engel oluşturan faktörlere ilişkin görüş ve düşünceleri nelerdir?

3. Özel eğitim alanında çalışan öğretmenlerin yardımcı teknolojinin kullanımında destek stratejilerinin önemine ilişsin görüş ve düşünceleri nelerdir?

\section{Yöntem}

$\mathrm{Bu}$ araştırma tarama modelinde betimsel bir çalışmadır. Tarama modelleri; geçmişte veya halen var olan bir durumu, var olduğu şekli ile betimlemeyi amaçlayan araştırma yaklaşımıdır (Karasar, 2000). Bu araştırmada veri toplama aracı olarak Chmiliar (2007) tarafından geliştirilen anketten yararlanılmıştır. Öncelikle anketi geliştiren Athabaska Üniversitesi'nde görev yapan Linda Chmiliar'dan gerekli izin alınmıştır. Daha sonra anketin dilsel eşdeğerliği yapılmıştır. Anketin dilsel eşdeğerliği için yapılan işlem sırası aşağıda sunulmaktadir: 
1. Türkçe’ye iki bağımsız çevirisi (bir ingilizce öğretmeni ve ingilizce bölümünde görev yapan bir öğretim görevlisi) yapılmıştır.

2. Bu iki çeviri her iki dili akademik olarak çok iyi seviyede bilen bağımsız bir uzman tarafından birleştirilmiştir.

3. Birleştirilmiş Türkçe metin, İngilizceyi iyi bilen iki yabancı dil uzmanı tarafından tekrar orijinal dile (İngilizce) çevrilmiştir. Daha sonra anketin İngilizce ve Türkçe çevirisinin tutarlılığına bakılmıştır. Anketin İngilizce ve Türkçe çevirisinin tutarlı olduğu görülmüştür.

4. Türkçe anketin metni dilbilgisi, ifade anlaşılırlığı, yazım kuralları açısından Türkçe öğretmenliğinde görevli bir öğretim üyesi tarafından incelenmiş ve gerekli düzeltmeler yapılmıştır.

Kullanılan anketin başında, anketi dolduracak olan eğitimcilere yardımcı teknolojiler konusunda genel bir bilgi verilmiş, böylece öğretmenlerin anketle ilgili ön bilgi edinmeleri sağlanmıştır. Ayrıca anketin görünüş geçerliği yapılmıştır. Bu amaçla mevcut çalışmada anket maddeleri iki alan uzmanına gönderilerek görüş alınmıştır. Alan uzmanlarından gelen dönütlere göre katılımcıların yaş ve cinsiyetlerini belirleyici demografik sorular eklenmiştir. Anketin 7'nci, 8'inci, 12'nci ve 13'üncü soruları biçimsel olarak düzenlenip seçenekler eklenmiş ve anket görünüş geçerliğine uygun hale getirilmiştir.

\section{Veri Toplama Aracı}

$\mathrm{Bu}$ araştırmada özel eğitim alanında çalışan öğretmenlerin özel eğitimde yardımcı teknolojilerin kullanımıyla ilgili görüş ve düşüncelerinin belirlemek amacıyla kullanılan anket Athabaska Üniversitesinde görev yapan Linda Chmiliar tarafından alan uzmanlarının görüşleri doğrultusunda geliştirilmiştir. Ankette öğretmenlerle ilgili yaş, cinsiyet, mevcut görev, öğretim kademesi, mesleki kıdem, eğitime alma durumu, bilgi ve beceri düzeyi, memnuniyet, yardımcı teknolojileri kullanma sıklığı, bütçe durumu, yardımcı teknolojiye erişebilen öğrenci sayısını 
belirlemeye yönelik 13 soru, yardımcı teknolojilerin kullanımına engel oluşturan faktörleri belirlemek için 12, yardımcı teknolojilerle ilgili destek stratejilerinin önemini belirlemek için de 10 maddeden oluşan derecelendirme tipi cevaplar bulunmaktadır. Yardımcı teknolojinin kullanımına engel oluşturan maddelerin 10'u olumlu, 2'si ise olumsuz ifadeden oluşmaktadır. $\mathrm{Bu}$ kısımda maddelerin puanlaması 4'li Likert tipinde derecelendirilerek "1: Hiç Engel Oluşturmaz, 2: Biraz Engel Oluşturur, 3: Orta Derecede Engel Oluşturur, 4: Çok engel oluşturur” şeklinde ifade edilmiştir. Bu maddelerden elde edilecek yüksek puanlar, yardımc1 teknoloji kullanımına ne kadar engel oluşturduğu şeklinde yorumlanmaktadır. Yardımcı teknolojilerle ilgili destek stratejilerinin önemiyle ilgili maddelerin tümü olumlu ifadeden oluşmaktadır. Bu kısımda da maddelerin puanlaması 4'li Likert tipinde derecelendirilerek "1: Hiç Önemli Değil, 2: Biraz Önemli, 3: Orta Derecede Önemli, 4: Çok Önemli” şeklinde ifade edilmiştir. Bu maddelerden elde edilecek yüksek puanlar, yardımcı teknoloji kullanımıyla ilgili destek stratejilerinin ne derece önemli olduğu şeklinde yorumlanmaktadır.

\section{Verilerin Toplanması}

Veriler Hakkâri İl/İlçe Milli Eğitim Müdürlüklerine bağlı ilkokul, ortaokul ve lise kademesinde görev yapan özel eğitim öğretmenlerinden, özel eğitim ve rehabilitasyon merkezlerinden ve özel eğitim uygulama ve iş eğitim okulunda görev yapan öğretmenlere uygulanan “Özel Eğitimde Yardımcı Teknolojilerin Kullanım Anketi” ile elde edilmiştir. Araştırmanın verileri, öğretmenlerin çalıştıkları eğitim kurumlarına gidilerek birebir anket uygulaması ile gerçekleşmiştir. Anket ve araştırma konusu hakkında açıklama yapıldıktan sonra anketler dağıtılmış ve öğretmenlerden anketi doldurmaları istenmiştir. Anketler, gönüllü olarak dolduran öğretmenlerden geri toplanmıştır. Araştırma kapsamında 111'i erkek, 100’ü kadın olmak üzere toplam 211 öğretmenden veri toplanmıştır. 


\section{Verilerin Analizi}

Araştırmanın verileri SPSS 22.0 paket programı kullanılarak analiz edilmiştir. Veri analiz sürecinde frekans (f) ve yüzde (\%), aritmetik ortalama (X) ve standart sapma (SS) hesaplamalarına yer verilmiştir. Özel eğitim alanında çalışan öğretmenlerin yaş, cinsiyet, mevcut görev, öğretim kademesi, mesleki kıdem, eğitime alma durumu, bilgi ve beceri düzeyi, memnuniyet, yardımcı teknolojileri kullanma sıklığı, bütçe durumu, yardımcı teknolojiye erişebilen öğrenci sayısını belirlemeyle ilgili bilgilerin raporlaştırılmasında frekans ve yüzde; yardımcı teknolojilerin kullanımına engel oluşturan faktörlerin ve destek stratejilerinin raporlaştırılmasında ise aritmetik ortalama ve standart sapma değerlerine ulaşılmıştır.

\section{Çalışma Grubu}

Bu araştırmanın çalışma grubunu 2017 - 2018 eğitim-öğretim yılında Hakkâri ili ve ilçelerinde özel eğitim alanında çalışan öğretmenler oluşturmuştur. Öğretmenlerin yaş, cinsiyet, mevcut görev, öğretim kademesi, mesleki kıdem, eğitime alma durumu, bilgi ve beceri düzeyi, memnuniyet, yardımcı teknolojileri kullanma sıklığı, bütçe durumu ve yardımcı teknolojilere erişebilen öğrenci sayısına ilişkin özellikler Tablo 1'de özetlenmiştir.

Tablo 1. Araştırmaya Katılan Öğretmenlerin Sosyo-Demografik Özellikleri.

\begin{tabular}{|c|c|c|}
\hline Değişkenler & $\begin{array}{l}\text { Frekans } \\
\text { (f) }\end{array}$ & $\begin{array}{c}\text { Yüzde } \\
(\%)\end{array}$ \\
\hline \multicolumn{3}{|l|}{ Yaş } \\
\hline $17-25$ yaşıında & 93 & 44,1 \\
\hline $26-30$ yaşında & 90 & 42,7 \\
\hline 31-35 yaşında & 23 & 10,9 \\
\hline 36 yaş ve üzeri & 5 & 2,3 \\
\hline \multicolumn{3}{|l|}{ Cinsiyet } \\
\hline Erkek & 111 & 52,6 \\
\hline Kadın & 100 & 47,4 \\
\hline \multicolumn{3}{|l|}{ Mevcut Görev } \\
\hline Özel Eğitim Öğretmeni & 157 & 74,4 \\
\hline Branş Öğretmeni (Beden Eğitimi vs.) & 36 & 17,1 \\
\hline Psikolog/Rehber Öğrt. & 14 & 6,6 \\
\hline Müdür/Müdür Yardımcısı & 4 & 1,9 \\
\hline \multicolumn{3}{|l|}{ Öğrenim Kademesi } \\
\hline Okul Öncesi/Anasınıfı & 28 & 13,2 \\
\hline 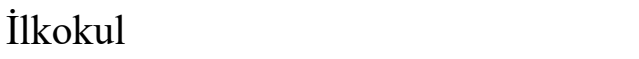 & 116 & 55,0 \\
\hline
\end{tabular}


YYÜ Eğitim Fakültesi Dergisi (YYU Journal of Education Faculty), 2018; 15(1):1540-1569, http://efdergi.yyu.edu.tr

http://dx.doi.org/10.23891/efdyyu.2018.115

ISSN: 1305-020

Ortaokul

Lise

$16 \quad 7,6$

Okul Konumu

Şehir Merkezi

Kirsal Alan

163

77,3

Okul Mevcudu

1-100 öğrenci

48

22,7

101-250 öğrenci

25,1

251-500 öğrenci

23,7

500 'den fazla öğrenci

24,7

Görev Süresi

1-5 Y1l

53

50

26,5

6-10 Y1

187

88,6

11-15 Y11

17

5

8,1

15 Yildan Fazla

2

Hizmet içi Ĕ̆itim Alma Durumu

Evet

\section{7}

2,4

Hayır

144

31,8

Mevcut Bilgi ve Becerilerinden Memnun Olma Durumu

Memnun Değilim

Biraz Memnunum

29

68,2

Orta Düzeyde Memnunum

13,8

Çok Memnunum

$57 \quad 27,0$

Bilgisayarı Sınıfta Kullanma Sıklığı

Her gün

Haftada 2-3 kez

$106 \quad 50,2$

Haftada $1 \mathrm{kez}$

19

Hiç

Öğrencilere Yardımcı Teknolojileri Öğretme Durumu

$0-5$ öğrenci

6-10 öğrenci

11-15 öğrenci

1

9

9,0

16'dan fazla öğrenci

\section{7}

26

29

139

8,1

12,3

13,7

65,9

Öğretmenlerin Kullandıkları Teknolojilerin Bütçe Desteği

Kişi

Kurum

165

78,2

28

7

13,3

$11 \quad 5,2$

Bilmiyorum

Yardımcı Teknolojileri Kullanması Gereken Ancak Bir Şekilde

Erişemeyen Öğrenciler

\begin{tabular}{lcc}
\hline Evet & 119 & 56,4 \\
Hayır & 60 & 28,4 \\
Bilmiyorum & 32 & 15,2 \\
\hline
\end{tabular}

Tablo 1'e göre araştırmaya öğretmenlerin 93'ü 17-25, 90'1 26-30, 23'ü 31-35 yaş aralığında ve 5'i ise 36 yaşından büyüktür. Bu öğretmenlerin 111'i erkek, 100'ü ise kadındır. Aynı zamanda öğretmenlerin 157'si özel eğitim öğretmeni, 36's1 branş öğretmeni, 14'ü 
psikolog/rehber öğretmen ve son olarak 4’ü müdür/müdür yardımcısı olarak görev yapmaktadır. Görev yapılan kademeye bakıldığında öğretmenlerin 28'i okul öncesi/anasınıfı öğretmeni, 116'sı ilkokul, 51'i ortaokul ve son olarak 16'sı lise öğretmenidir. Çalışılan okulların mevcuduna bakıldığında 53 öğretmen 1-100 öğrencili okulda, 50 öğretmen 101-250 öğrencili okulda, 52 öğretmen 251-500 öğrencili okulda çalışırken 56 öğretmen ise 500’den fazla öğrenciye sahip okullarda görev yapmaktadır. Öğretmenlerin tecrübe durumuna bakıldığında 187 öğretmen 1-5 y1l, 17 öğretmen 6-10 yıl, 5 öğretmen 11-15 yıl, 2 öğretmen ise 15 yıldan fazla görev yapmaktadır. Bu öğretmenlerin hizmet içi eğitim ya da kurs alma değişkenine göre dağılım durumuna bakıldığında 67 öğretmen eğitim almış, 144 öğretmen ise eğitim almamıştır. Öğretmenlerin mevcut bilgi ve becerilerinden memnun olma durumları sorulduğunda 29 öğretmen memnun olmadığını, 57 öğretmen biraz memnun olduğunu, 106 öğretmen orta düzeyde memnun olduğunu, 19 öğretmen ise çok memnun olduğunu belirtmiştir. Öğretmenlerin bilgisayarı sınıfta kullanma sıklığı incelendiğinde 17 öğretmen her gün, 26 öğretmen haftada 2-3 kez, 29 öğretmen haftada 1 kez kullandığını belirtirken 139 öğretmen ise sınıfta yardımcı teknolojileri hiç kullanmadıklarını belirtmişlerdir. Öğretmenlerin 165 'i 0-5 öğrenciye, 28'i 6-10 öğrenciye, 7'si 11-15 öğrenciye, 11'i ise 16'dan fazla öğrenciye yardımc1 teknoloji araçlarını kullanmayı öğretmişlerdir. Öğretmenlerin kullandıkları yardımcı teknolojilerin bütçe desteği incelendiğinde 30 öğretmenin kişi tarafından, 110 öğretmenin kurum tarafından desteklendiği 71 öğretmen ise bütçe kaynağını bilmediğini ifade etmiştir. Son olarak bu öğretmenlerin 119'u “Sınıfınızda yardımcı teknolojileri kullanması gereken ancak bir şekilde erişemeyen öğrencileriniz oldu mu?" sorusunda "evet” cevabını verirken 60’1 "hayır" cevabını vermiş, 32 öğretmen ise bu konuda herhangi bir bilgisi olmadığını ifade etmiştir. 


\section{Bulgular}

Araştırmanın alt amacı "Araştırmaya katılan eğitimcilerin yardımcı teknoloji kullanımına ilişkin engel oluşturan faktörler nelerdir?” şeklinde ifade edilmiş ve Yardımcı Teknolojilerin Kullanımına İlişkin Engel Anketiyle toplanan verilere ait standart sapma ve aritmetik ortalama değerleri Tablo 2'de verilmiştir.

Tablo 2. Yardımcı Teknoloji Kullanımına İlişkin Engel Anketiyle Toplanan Verilere Ait Standart Sapma ve Aritmetik Ortalama Değerleri.

\begin{tabular}{llcc}
\hline & $\mathbf{X}$ & $\mathbf{S S}$ \\
\hline 1. & Yardımcı teknolojiyle ilgili bilgi birikimi eksikliği & 2,83 & 1,02 \\
2. Potansiyel/olası yardımcı teknoloji kullanıcılarının tespit edilememesi ve & 2,68 & 0,91 \\
& & \\
değerlendirilememesi & 2,79 & 1,05 \\
3. Yardımcı teknolojiyle ilgili eğitim fırsatlarının olmaması & 2,73 & 1,03 \\
4. Yardımcı teknolojiyle ilgili bilgi eksikliği & 2,64 & 1,00 \\
5. Yardımcı teknoloji kullanımıyla ilgili yeterli olabilmek için gereken & & \\
& zamanın olmaması & 2,73 & 0,96 \\
6. Yardımcı teknoloji araç-gereçlerini programlamak için gereken zamanın & & \\
& olmaması & 2,96 & 1,04 \\
7. Öğrenciler için yardımcı teknoloji araç-gereçlerinin eksikliği & 2,85 & 0,96 \\
8. Sinıfta yardımcı teknolojilerin etkili kullanımı konusunda gerekli & & \\
$\quad$ desteğin olmaması & 2,85 & 0,97 \\
9. Yardımcı teknoloji araç-gereçlerin bakımı için gerekli teknik desteğin & & \\
$\quad$ olmaması & 2,91 & 0,98 \\
10. Yardımcı teknoloji araç-gereçlerinin ve programların karmaşılığı & 3,06 & 0,96 \\
11. Yardımcı teknoloji araç-gereçlerinin masrafları & 2,76 & 1,08 \\
12. Aileden, yöneticilerden vb. kişiler tarafından yardımcı teknolojinin kabul & & \\
$\quad$ görmemesi & 2,81 & 0,99 \\
\hline
\end{tabular}

Tablo 2'ye bakıldığında katılımcı öğretmenlerin "Yardımcı teknolojiyle ilgili bilgi birikimi eksikliği” madde ortalamasına bakıldığında 2,83, "Potansiyel/olası yardımcı teknoloji kullanıcılarının tespit edilememesi ve değerlendirilememesi” madde ortalamasına bakıldığında 2,68, "Yardımcı teknolojiyle ilgili eğitim firsatlarının olmaması" için 2,79, "Yardımcı teknolojiyle ilgili bilgi eksikliği” için 2,73, "Yardımcı teknoloji kullanımıyla ilgili yeterli olabilmek için gereken zamanın olmaması" için 2,64, "Yardımcı teknoloji araç-gereçlerini programlamak için gereken zamanın olmaması” için 2,73, “Öğrenciler için yardımcı teknoloji 
araç-gereçlerinin eksikliği” için 2,96, "Sınıfta yardımcı teknolojilerin etkili kullanımı konusunda gerekli desteğin olmaması" için 2,85, "Yardımcı teknoloji araç-gereçlerin bakımı için gerekli teknik desteğin olmaması" için yine aynı şekilde 2,85, "Yardımcı teknoloji araçgereçlerinin ve programların karmaşıklığı" için 2,91, "Yardımcı teknoloji araç-gereçlerinin masrafları" için 3,06 ve "Aileden, yöneticilerden vb. kişiler tarafından yardımcı teknolojinin kabul görmemesi” maddesi için ortalama 2,76 şeklinde ortaya çıkmıştır. Son olarak toplam puan ortalaması 2,81, standart sapmanın ortalaması ise 0,99 çıkmıştır.

Araştırmanın diğer bir alt amacı "Araştırmaya katılan öğretmenlerin yardımcı teknoloji destek stratejilerinin önemiyle alakalı görüşleri nelerdir?” şeklinde ifade edilmiş ve Yardımcı Teknoloji Destek Stratejisi Önem Anketi ile toplanan verilere ait standart sapma ve aritmetik ortalama değerleri Tablo 3'de verilmiştir.

Tablo 3. Yardımcı Teknoloji Destek Stratejisi Önemi Anketiyle Toplanan Verilere Ait Standart Sapma ve Aritmetik Ortalama Değerleri.

\begin{tabular}{lcc}
\hline & X & SS \\
\hline 1. Yardımcı teknolojiyle ilgili eğitimin olması & 3,63 & 0,67 \\
2. Öğretmenlere veya öğrencilere yardımcı teknolojiyle ilgili araç-gereç & 3,55 & 0,71 \\
eğitimi & & \\
3. Yardımcı teknolojiyle ilgili hizmet-içi eğitim için gerekli zaman & 3,28 & 0,84 \\
4. Yardımcı teknoloji araç-gereçlerinin kurulumunu, kullanıcı ayarlarını, & 3,30 & 0,79 \\
programlamasını yapmak için gerekli zaman & & \\
5. Yardımcı teknolojiyle ilgili teknik desteğe erişim & 3,45 & 0,68 \\
6. Yardımcı teknolojiyle ilgili sınıf programlaması için eğitim desteği & 3,35 & 0,78 \\
7. Yardımcı teknoloji araç-gereçlerinin bulunması & 3,55 & 0,70 \\
8. Yardımcı teknolojilerle ilgili kullanım kılavuzları, yazılı materyaller/el & 3,37 & 0,79 \\
kitapçıkları & & \\
9. Yardımcı teknolojiyle ilgili internet üzerinden canlı destek sağlanması ve & 3,24 & 0,85 \\
kullanım kılavuzları & 3,64 & 0,71 \\
10. Yardımcı teknolojilerle ilgili parasal/maddi destek & 3,43 & 0,75 \\
Toplam Ortalama &
\end{tabular}

Tablo 3'e bakıldığında katılımcı öğretmenlerin "Yardımcı teknolojiyle ilgili eğitimin olması" madde ortalamasına bakıldığında 3,63, "Personel veya öğrencilere yardımcı teknolojiyle ilgili araç-gereç eğitimi" madde ortalamasına bakıldığında 3,55, "Yardımcı teknolojiyle ilgili hizmet-içi eğitim için gerekli zaman" madde ortalamasına bakıldığında 3,28, 
"Yardımcı teknoloji araç-gereçlerinin kurulumunu, kullanıcı ayarlarını, programlamasını yapmak için gerekli zaman" madde ortalamasına bakıldığında 3,30, "Yardımcı teknolojiyle ilgili teknik desteğe erişim" madde ortalamasına bakıldığında 3,45, "Yardımcı teknolojiyle ilgili sınıf programlaması için eğitim desteği” madde ortalamasına bakıldığında 3,35, "Yardımcı teknoloji araç-gereçlerinin bulunması" madde ortalamasına bakıldığında 3,55, "Yardımcı teknolojilerle ilgili kullanım kılavuzları, yazılı materyaller/el kitapçıkları" madde ortalamasına bakıldığında 3,37, "Yardımcı teknolojiyle ilgili internet üzerinden canlı destek sağlanması ve kullanım kılavuzları" madde ortalamasına bakıldığında 3,24 ve son olarak "Yardımcı teknolojilerle ilgili parasal/maddi destek" maddesi için ortalama 3,64 şeklinde ortaya çıkmıştır. Son olarak toplam ortalama değerine baktığımızda toplam ortalama 3,43, standart sapma ortalaması ise 0,75 çıkmıştır.

\section{Tartışma}

Bu çalışmada elde edilen veriler özel eğitim alanında çalışan öğretmenlerin demografik bilgilerinin yanı sıra, yardımcı teknolojilerle ilgili hizmet-içi eğitim durumlarını, yardımcı teknoloji alanında mevcut bilgi ve becerilerinden ne derece memnun olduklarını, hangi kademedeki öğrencilerle çalıştıklarını, yardımcı teknolojilerin kullanımına engel oluşturan faktörleri ve destek stratejilerinin neler olduğunu ortaya koymuştur.

Analiz sonucunda ilk olarak, araştırmaya katılan öğretmenlerin \% 68,2'si (n=144) yardımcı teknolojilerle ilgili hizmet-içi eğitim almadıklarını belirtmişlerdir. Yapılan benzer araştırmalarda da öğretmenler, yardımcı teknolojilerle ilgili yeterli düzeyde hizmet-içi eğitim almadıklarını ve buna bağlı olarak yardımcı teknolojileri kullanma konusunda kendilerini yeterli hissetmediklerini belirtmişlerdir (Alkahtani, 2013; Ashton, Lee ve Vega, 2005; Bausch ve Hasselbring, 2004; Parette, Peterson-Karlan, Smith, Gray, ve Silver-Pacuilla, 2006; Smith ve Kelley, 2007; Wilcox, Guimond, Campbell, ve Moore, 2006). Yardımcı teknolojilerin etkili bir şekilde kullanılmasında öğretmenlere verilecek nitelikli hizmet içi eğitimin yanı sıra, 
okullarda gereksinim duyulan teknik destek personellerinin bulundurulması ya da internet üzerinden yardım alabilecekleri canlı destek hizmetlerinin önemli olabileceği düşünülmektedir.

İkinci olarak, öğretmenlerin \% 40,8’i (n=86) yardımcı teknolojilerle ilgili mevcut bilgi ve becerilerinden memnun olmadıklarını, \% 59,2'si $(n=125)$ yardımcı teknolojilerle ilgili mevcut bilgi ve becerilerinden orta düzeyde memnun olduklarını ya da çok memnun olduklarını belirtmişlerdir. Ancak bu bulgunun Hakkâri ilindeki resmi ve özel eğitim kurumlarının envanter listesinde bulunan mevcut yardımcı teknolojilerin düzeyiyle ilişkili olabileceği düşünülmektedir. Daha önce de söz edildiği gibi Hakkâri İl Milli Eğitim Müdürlüğü’ne bağlı kurumların envanter listesinde sınırlı düzeyde ileri düzey yardımcı teknolojinin (akıllı tahta, bilgisayar) bulunduğu ve genel olarak düşük düzey yardımc1 teknolojilerin (resimli kartlar/fotoğraf, fosforlu işaretleyiciler, okuma kalemleri, vb.) bulunduğu rapor edilmiştir. Diğer yandan araştırmaya katılan öğretmenlerin \% 65,9’u (n=139) öğrencilerinin sınıfta ileri düzey yardımcı teknolojileri kullanmadıklarını (akıllı tahta/bilgisayar), \% 26’sı ( $\mathrm{n}=55)$ da öğrencilerinin ileri düzey yardımcı teknolojileri haftada sadece birkaç kez kullandığını belirtmişlerdir. Dolayısıyla düşük düzey yardımcı teknoloji araç-gereçleriyle ilgili teknik (yazılım, donanım vb.) sorunların daha az olabileceği ve bu durumun öğretmenlerin yardımcı teknolojilerle ilgili memnuniyet düzeylerini etkilemiş olabileceği düşünülmektedir.

Araştırmaya katılan öğretmenler yardımcı teknolojilerin kullanımı konusunda en çok engelleyen faktörleri; araç-gereçlerin maliyeti, araç gereçlerin ve yazılımların karmaşıklığı, okullarda öğrenciler için yeteri kadar yardımcı teknoloji araç-gereçlerinin bulunmaması, yardımcı teknolojilerle ilgili bilgi eksikliği ve okullarda araç-gereçlerin bakımı için gereken teknik desteğin olmaması olarak sıralamışlardır. Bu çalışmadan elde edilen bulgular alanyazındaki diğer araştırmalarda elde edilen bulguları destekler niteliktedir (Alammary, Al- 
Haiki ve Al-Muqahwi, 2017; Alkahtani, 2013; Alper ve Raharinirina, 2006; Alves, Monteiro, Rabello, Gasparetto ve Carvalho, 2009; Bryant, Seok, Ok ve Bryant, 2012; Chmiliar, 2007; Copley ve Ziviani, 2004; Derer, Polsgrove ve Rieth 1996; Sydeski, 2013). Öğretmenler, yardımcı teknolojilerin kullanımında araç-gereçlerin maliyetini önemli bir engel olarak belirtmesinin yanı sıra çoğu zaman yardımcı teknoloji araç gereçlerinin zamanında teslim edilememesi ya da araç gereçlerin teknik şartnamelerinin uyuşmazlık göstermesi gibi ayrıntılı konular da öğretmenlere çeşitli zorluklar yaşatabilmektedir (Bryant ve diğ., 2012). Ayrıca kullanılan ileri düzey yardımcı teknoloji araç-gereçlerinin güncellenmesi, farklı yazılım veya donanım gerektirmesi gibi nedenlerle bütçe desteğinin sürdürülebilirliği de göz önünde bulundurulması gereken bir konudur (Copley ve Ziviani, 2004; Swinth ve Case-Smith, 1993). Yardımcı teknolojilerle ilgili bütçe desteğinin sağlanması ve sürdürülmesi konusunda okul yönetimleri farklı kurum veya kuruluşlarla işbirliği gerçekleştirilebilir (Tübitak, Avrupa Birliği Projesi, vb.). Yardımcı teknolojilerle ilgili maliyet sorunlarının çözümünde ise bütçe planlamasını ve ayarlanmasını sağlayabilecek danışmanlık şirketlerinden destek alınabilir.

Öğretmenler yardımcı teknolojilerin kullanımı konusundaki bir diğer önemli engelin yardımcı teknolojilerle ilgili bilgi eksikliği olduğunu belirtmişlerdir. Alanyazında yapılan benzer araştırmalarda bilgi eksikliğinin yardımcı teknolojilerin kullanımında önemli bir engel olduğu belirtilmiştir (Alkahtani, 2013; Alper ve Raharinirina, 2006; Tekinarslan ve Y1kmış, 2005; Todis, 1996). Bilgi eksikliğinin giderilmesi ve okullarda öğrenciler için yeteri kadar yardımcı teknoloji araç-gereçlerinin bulundurulması konusunda ülkemizde yapılan en geniş çaplı projenin "Fırsatları Arttırma ve Teknolojiyi İyileştirme Hareket” (FATİH) projesi olduğu söylenebilir. FATİH projesi kapsamında okullarda her derslik için etkileşimli tahta, öğretmen ve öğrenciler için de tablet bilgisayarlar verilmektedir. Proje kapsamında verilen teknolojik cihazların yanı sıra öğretmenlere "FATİH Projesi Eğitimde Teknoloji” , "Etkileşimli Sınıf Yönetimi” eğitimleri ve çeşitli uzaktan eğitimlerin verildiği belirtilmektedir (Milli Eğitim 
Bakanlığı (MEB), 2018). Ancak FATİH projesi kapsamında verilen hizmet-içi eğitimlerle ilgili öğretmen görüşlerinin incelendiği araştırmalarda hizmet-içi eğitimlerin yeterli olmadığı belirtilmiştir (Gökmen, Akgün ve Kartal, 2014; Sarıtepeci, Durak ve Seferoğlu, 2016; Vural ve Ceylan, 2014; Yıldız, Sarıtepeci ve Seferoğlu, 2013). Dolayısıyla yardımcı teknolojilerin kullanımına yönelik hizmet-içi eğitim faaliyetlerinin içeriklerinin yeniden düzenlenebileceği kapsamlı planlamaların yapılmasının önemli olabileceği düşünülebilir (Sarıtepeci ve diğg., 2016).

$\mathrm{Bu}$ araştırmada öğretmenlerin yardımcı teknolojilerin kullanımı konusunda belirttiği bir diğer önemli engel yardımcı teknoloji araç-gereçlerinin ve kullanılan programların karmaşıklığıdır. Bu duruma bağlı olarak araç-gereçlerin bakımı ve tamiri için gereken teknik desteğin olmaması da önemli bir engel olarak görülmüştür. $\mathrm{Bu}$ araştırma kapsamında okullardan istenen envanter listesinde yardımcı teknoloji cihazları olarak akıllı tahtaların, masaüstü/dizüstü bilgisayarların bulunduğu belirtilmiştir. Dolayısıyla öğretmenlerin bilgisayar teknolojisine sahip araç-gereçlerin kullanımında ve buna bağlı olarak teknik desteğe ulaşmada problem yaşadığı söylenebilir. Bu araştırmada elde edilen bulguların Judge'ın (2001) özel eğitim öğretmenlerinin bilgisayar teknolojisi kullanımı konusundaki görüş ve düşüncelerini incelediği araştırma bulgularıyla benzerlik gösterdiği söylenebilir. Judge (2001) yaptığı araştırmada toplam 91 özel eğitim öğretmeninden veri toplamıştır. Araştırma sonunda öğretmenler bilgisayar teknolojisiyle ilgili daha fazla eğitime ve teknik personele ihtiyaç duyduklarını belirtmişlerdir. Dolayısıyla okullarda öğretmenlere yardımcı teknoloji kullanımı konusunda karşılaşabilecekleri sorunların çözümünde bilgi ve eğitim desteği sağlayabilecek hizmet içi eğitim seminerlerinin düzenlenmesinin ve okullarda bilgi işlem uzmanlarının bulunmasının önemli olabileceği söylenebilir.

Araştırmaya katılan öğretmenler yardımcı teknolojilerin kullanımı konusunda en önemli destek stratejilerini; bütçe desteği, eğitim desteği, araç-gereç desteği ve araç-gereçlerin 
kullanımında gereken teknik desteğe erişim olarak belirtmişlerdir. $\mathrm{Bu}$ araştırmada öğretmenlerin belirtmiş oldukları en önemli destek stratejileri, Chmiliar (2007) tarafından gerçekleştirilen araştırmanın bulgularıyla benzerlik göstermektedir. Yardımcı teknolojilerin kullanımında bütçe desteğinin çeşitli araştırmalarda en önemli destek stratejileri arasında olduğu gösterilmektedir (Chmiliar, 2007; Copley ve Ziviani, 2004; Gustafson, 2006; Tekinarslan ve Yıkmış, 2005) . Diğer yandan alanyazında yapılan bazı çalışmalarda bütçe desteğinin yardımcı teknolojilerin kullanımı konusunda sağlanabilecek hizmet-içi eğitim ve yardımcı teknoloji araç-gereçlerinin alımını doğrudan etkileyebileceği vurgulanmıştır (Inge, 2003; Peters, 1999). Çeşitli araştırmalarda olduğu gibi yapılan bu araştırmada da öğretmenler yardımcı teknoloji kullanımında en önemli destek stratejisinin bütçe desteği olduğunu belirtmiştir. Okullara yardımcı teknolojilerin kullanımında bütçe desteği sağlanabilecek eğitim politikaları belirlenerek daha fazla sayıda proje ve planlama gerçekleştirilebilir.

Araştırmaya katılan öğretmenler yardımcı teknolojilerin kullanımında bir diğer önemli destek stratejisinin eğitim desteği olduğunu belirtmiştir. Okullarda görev yapan öğretmenlere eğitim desteğinin sağlanmasında hizmet-içi eğitim uygun bir seçenek olabilir. Öğretmen adayları için ise öğretmen yetiştirme lisans programlarında yer alan derslerle ilgili güncellemelerin önemli olabileceği düşünülmektedir. Ülkemizde özel eğitim öğretmenliği lisans programında güncelleme yapılarak “Özel Eğitimde Teknoloji Destekli Öğretim” dersi müfredata eklenmiştir. Ancak öğretmenlerin yardımcı teknolojileri etkili bir şekilde kullanabilmeleri için daha fazla eğitim desteğine ve daha güncel öğretim modellerine ya da uygulamalarına gereksinimleri olduğu söylenebilir.

Öğretmenlerin ve öğretmen adaylarına yönelik yardımcı teknolojilerle ilgili eğitim desteğinin sağlanmasında uzaktan eğitim sistemi bir seçenek olarak düşünülebilir. Örneğin; Kanada'nın Ontario eyaletine bağlı Athabasca Üniversitesi’nde öğretmen adayları için yardımcı teknolojilerle ilgili internet ortamı üzerinden ulaşılabilen bir tür eğitim portalı 
geliştirilmiştir. İzleyen satırlarda eğitim portalıyla ilgili bir takım açıklamalara değinilmiştir. Öğretmen adayları eğitim portalından video görüntülerine erişerek yardımcı teknolojilerle ilgili bilgi ve becerilerini geliştirebilmekte ve yardımcı teknolojilerin sınıfta nasıl uygulanabileceğini öğrenmektedirler. Etkileşimi artırmak adına da eğitim portalında öğretmen adaylarının internet üzerinden çevrimiçi olarak tartışma forumlarına katılmaları, bilgi ve deneyimlerini paylaşmaları beklenmektedir. Sonuç olarak Athabasca Üniversitesinde geliştirilen eğitim portalının ülkemizde görev yapan öğretmen ve öğretmen adayları için model oluşturabileceği düşünülebilir.

Ülkemizde bu konuyla ilgili yayımlanmamış lisansüstü tez çalışması olarak ise bir araştırma yapılmıştır (Özdamar, 2016). Yapılan çalışma izleyen satırlarda kısaca özetlenmektedir. Araştırmada özel eğitim öğretmenlerinin sınıflarında kullandıkları yardımcı teknolojilere ilişkin görüşleri incelenmiştir. Araştırmada toplam 414 özel eğitim öğretmeninden veri toplanmış ve veri toplama aracı olarak araştırmacı tarafından geliştirilen "Yardımcı Teknoloji Kullanım Anketi” kullanılmıştır. Araştırmanın bulgularına göre çalışmaya katılan öğretmenler yardımcı teknolojileri kullanmada yaşadıkları en büyük sorunları; "yardımcı teknolojiye ulaşma", "teknik destek" ve "yardımcı teknolojilerle ilgili yeterli bilgi sahibi olmamak" olarak sıralamışlardır. Özdamar (2016)'ın elde ettiği bulguların, bu araştırmada öğretmenlerin yardımcı teknolojilerin kullanımında en büyük engel olarak gördüğü bulgularla benzerlik gösterdiği söylenebilir.

$\mathrm{Bu}$ araştırmanın bazı açılardan sınırlılıklar taşıdığı düşünülebilir. İlk olarak, bu araştırma yardımcı teknolojilerin kullanımında sadece özel eğitim öğretmenlerinin görüşlerinin incelenmesiyle sınırlıdır. İleri araştırmalarda yardımcı teknolojilerin kullanımında aile üyelerinin (anne, baba, kardeş vb.), sağlık personellerinin ya da dil ve konuşma uzmanlarının görüş ve düşüncelerinin incelenebileceği araştırmalar planlanabilir. 
İkinci olarak, bu araştırmadan elde edilen veriler Hakkâri il Milli Eğitim Müdürlüğü’ne bağl1 okul öncesi eğitim, ilköğretim ve ortaöğretim kademelerinde görev yapan öğretmenlerin görüşleriyle sınırlıdır. Ülkemizde yapılan bir araştırmada özel gereksinimli üniversite öğrencilerinin yardımcı teknolojiyi kullanma düzeyleri incelenmiştir (Arslan-Arı ve İnan, 2010). Yapılan araştırma sonunda araştırmaya katılan 22 üniversite öğrencisinin dokuzu bilgisayarı haftada 10 saat ve üzerinde kullandığını belirtmiştir. Dolayısıyla üniversitede öğrenim gören özel gereksinimli öğrencilerin yardımcı teknolojiyi kullanma düzeylerinin farklı olduğu söylenebilir. İleri araştırmalarda üniversitede görev yapan öğretim elemanlarının özel eğitimde yardımcı teknolojilerin kullanımı konusundaki görüşlerinin incelenebileceği araştırmalar planlanabilir.

Üçüncü olarak bu araştırmada veri toplama aracı olarak Chmiliar'in (2007) geliştirdiği anketten yararlanılmıştır. Ankette öğretmenlerden elde edilen demografik bilgiler öğretmenlerin cinsiyeti, yaşı, okullardaki mevcut görevleri, hizmet içi eğitim alıp almadıkları vb. bilgilerle sınırlıdır. Ancak ankette öğretmenlerin eğitim düzeyleriyle (lisans, yüksek lisans, doktora) ilgili demografik sorular yer almamıştır. İleri araştırmalarda öğretmenlerin yardımcı teknolojilerle ilgili var olan bilgi ve becerilerinin aldıkları eğitim düzeyiyle ilişkili olup olmadığını inceleyen çalışmalar yapılabilir. Ayrıca ankette öğretmenlerin sınıflarında yardımcı teknolojiyi daha çok hangi becerilerin (sosyal, akademik, özbakım, vb.) öğretiminde kullandıklarını ortaya koyan sorular yer almamıştır. Yardımcı teknolojilerle ilgili yapılan alanyazın çalışmalarında yardımcı teknolojilerin akademik becerilerin öğretiminde sıklıkla kullanıldığı belirtilmektedir (Alper ve Raharinirina, 2006; Edyburn, 2001). Örneğin okumayazma öğretiminde yardımcı teknolojilerin kullanımının çok önemli olduğu vurgulanmıştır (Flanagan, Bouck ve Richardson, 2013; MacArthur, Ferretti, Okolo ve Cavalier, 2001). Başka bir çalışmada teknolojinin okuma zorluğu yaşayan özel gereksinimli bireylerin motivasyonlarını artırdığı belirtilmiştir (Reisberg, 2009; Sydeski, 2013). İleri araştırmalarda 
öğretmenlerin yardımcı teknolojileri hangi tür becerilerin öğretiminde kullandıklarının belirlenmesine yönelik araştırmalar planlanabilir.

\section{Makalenin Bilimdeki Konumu}

Eğitim Bilimleri / Özel Eğitim Anabilim Dalı

\section{Makalenin Bilimdeki Özgünlüğü}

$\mathrm{Bu}$ araştırmada özel eğitim öğretmenlerinden veri toplanmıştır. Bu araştırmada veri toplama aracı olarak kullanılan anket Türkiye'de ilk kez uygulanmıştır. Ulusal alanyazında özel eğitim öğretmenlerinin yardımcı teknolojilerin kullanımı konusundaki görüşlerini ortaya koyan yayımlanmış bir anket çalışmasının olmamasının bu çalışmanın ulusal alanyazına önemli bir katkı sağlayabileceği düşünülmektedir. Bu çalışmanın sonucunda özel eğitim sınıflarında yardımcı teknolojilerin kullanımına engel oluşturan faktörlerin belirlenmesi, gerekli düzenlemelerin yapılarak uygulanabilecek destek stratejilerinin sağlanması, eğitim politikalarının geliştirilmesi ve ileri de yapılabilecek bilimsel araştırmalara katkı sağlayabileceği düşünülmüştür.

\section{Kaynakça}

Alammary, J., Al-ha1k1, F. ve Al-muqahwi, K. (2017). The impact of assistive technology on down syndrome students in Kingdom of Bahrain. The Turkish Online Journal of Educational Technology, 16, 103-119.

Alkahtani, K. D. F. (2013). Teachers' knowledge and use of assistive technology for students with special educational needs. Journal of Studies in Education, 3, 65-86.

Alper, S., ve Raharinirina, S. (2006). Assistive technology for individuals with disabilities: A review and synthesis of literature. Journal of Special Education Technology, 21, 4756. 
Alquraini, T., ve Gut, D. (2012). Critical components of successful inclusion of students with severe disabilities: Literature review. International Journal of Special Education, 27, $42-59$.

Alves, C. C. F., Monteiro, G. B. M., Rabello, S., Gasparetto, M .E. R. F., ve Carvalho, K. M. (2009). Assistive technology applied to education of students with visual impairment. Revista Panam Salud Publica, 26, 148-52.

Arslan-Arı, İ., ve İnan, F. A. (2010). Assistive Technologies for students with disabilities: A survey of Access and use in Turkish universities. The Turkish Online Journal of Educational Technology, 9, 40-45.

Aslan, C. (2018). Özel eğitim öğretmenlerinin yardımcı teknolojilere yönelik tutumları. Ĕ̆itim Teknolojisi Kuram ve Uygulama, 8, 102-120.

Ashton, T., Lee, Y., ve Vega, L. A. (2005). Assistive technology: Perceived knowledge, attitudes, and challenges of AT use in special education. Journal of Special Education Technology, 20, 60-63.

Bausch, M. E., ve Hasselbring, T. S. (2004). Assistive technology: Are the necessary skills and knowledge being developed at the preservice and inservice levels? Teacher Education and Special Education, 27, 97-104.

Bryant, B. R., Seok, S., Ok, M., ve Bryant, D. P. (2012). Individuals with intellectual and/or developmental disabilities use of assistive technology devices in support provision. Journal of Special Education Technology, 27, 41-57.

Carey, D. M., ve Sale, P. (1994). Practical considerations in the use of technology to facilitate the inclusion of students with severe disabilities. Technology and Disability, 3, 7786. 
Chmiliar, L. (2007). Perspectives on assistive technology: What teachers, health professionals, and speech and language pathologists have to say. Developmental Disabilities Bulletin, 35, 1-17.

Coleman, M. B., Cramer, E. S., Park, Y., ve Bell, S. M. (2015). Art educators' use of adaptations, assistive technology, and special education supports for students with physical, visual, severe and multiple disabilities. Journal of Developmental and Physical Disabilities, 27, 637-660.

Copley, J., ve Ziviani, J. (2004). Barriers to the use of assistive technology for children with multiple disabilities. Occupational Therapy International, 11, 229-243.

Deniz, L., ve Demirkıran, A. V. (2006). Özel Eğitim Meslek Elemanlarının Bilgisayar Tutumları ve Bilgisayar Destekli Özel Eğitime Yönelik Görüșleri ve Yeterlilik Seviyeleri. M. Ü. Atatürk Ĕ̈itim Fakültesi Ĕ̆itim Bilimleri Dergisi, 24, 59-74.

Derer, K., Polsgrove, L., Rieth, H. (1996). A survey of assistive technology applications in schools and recommendations for practice. Journal of Special Education Technology, $2,62-80$.

Edyburn, D. L. (2001). 2000 in review: A synthesis of the special education technology literature. Journal of Special Education Technology, 16, 5-25.

Flanagan, S., Bouck, E. C., ve Richardson, J. (2013). Middle school special education teachers' perceptions and use of assistive technology in literacy instruction. Assistive Technology. 25, 24-30.

Gökmen, Ö. F., Akgün, Ö. E., Kartal, F. (2014). Fatih projesinde kullanılan etkileşimli tahtalara ve hizmet içi eğitimlere yönelik öğretmen görüşleri. Milli Eğitim Dergisi, 204, 42-62.

Gustafson, G. S. (2006). The assistive technology skills, knowledge, and Professional development needs of special educators in South western virginia. Unpublished Doctoral Dissertation, Virginia Polytechnic Institute and StateUniversity. 
Hutinger, P. L., Hall, S., Johansen, J., Robinson, L., Stoneburner, R., ve Wisslead, K. (1994). State of practice: How assistive Technologies areused in educational programs of children with multiple disabilities. a final report for the project: effective use of technology to meet educational goals of children with disabilities. Washington, DC: Western Illinois University.

Inge, C. (2003). Assistive Technology in Virginia's Pre K-12 Public Education System: A Policy Study. Unpublished Doctoral Dissertation. Washington, DC: George Washington University.

Johnston, L., Beard, L. A., ve Carpenter, L. B. (2007). Assistive technology: Access for all students. Columbus, OH: Pearson Merrill Prentice Hall.

Johnston, C., Thurlow, M., Altman, J., Timmons, J., ve Kato, K. (2009). Assistive technology approaches for large-scale assessment: Perceptions of teachers of students with visual. Impairments Exceptionality, 17, 66-75.

Judge, S. L. (2001). Computer applications in programs for young children with disabilities: Current status and future directions. Journal of Special Education Technology, 16, 2940.

Karasar, N. (2000). Bilimsel araştırma yöntemi. Ankara: Nobel Yayın Dağıtım.

Kışla, T. (2008). Özel eğitim öğretmenlerinin bilgisayar tutumlarının incelenmesi. Ege Ĕgitim Dergisi, 9, 128-154.

MacArthur, C.,Ferretti, R. P., Okolo, C. M., ve Cavalier, A. R. (2001). Technology applications for students with literacy problems: A critical review. Elementary School Journal, 101, 273-301.

McGregor, G., ve Pachuski, P. (1996). Assistive technology in schools: Are teachers ready, able, and supported? Journal of Special Education Technology, 13, 4-15. 
MEB, (2018). http://fatihprojesi.meb.gov.tr/ogretmen-egitimi-2/ adresinden 20.08.2018 tarihinde erişilmiştir.

Özdamar, O. (2016). Öğretmenlerin özel ĕgitim sınıflarında yardımcı teknoloji kullanımına ilişkin görüşlerinin belirlenmesi. Yayımlanmamış Yüksek Lisans Tezi. Eskişehir: Anadolu Üniversitesi Eğitim Bilimleri Enstitüsü.

Parette, H. (1997). Assistive technology devices and services. Education and Training in Mental Retardation and Developmental Disabilities, 32, 267-80.

Parette, H. P., Peterson-Karlan, G. R., Smith, S., Gray, T., ve Silver-Pacuilla, H. (2006). The state of assistive technology: Themes from an outcomes summit. Assistive Technology Outcomes and Benefits, 3, 15-33.

Parker, S., Buckley, W., Truesdell, A., Riggio, M., Collins, M., ve Boardman, B. (1990). Barriers to the use of assistive technology with children: A survey. Journal of Visual Impairment and Blindness, 84, 532-533.

Peters, S. W. (1999). Assistive Technology Issues in Virginia Schools: A five year follow-up study. Unpublished Doctoral Dissertation. Virginia: George Mason University.

Reed, P., ve Bowser, G. (2005). Assistive technology and the IEP. D. Edyburn, K.Higgins, ve R. Boone (Ed.), Handbook of special education technology research and practice içinde (s. 61-77). Whitefish Bay, WI: Knowledge by Design.

Reisberg, L. (2009). In expensive assistive technology for struggling readers. Closing the Gap, $28,22-24$.

Sani-Bozkurt, S. (2017). Özel eğitimde dijital destek: Yardımcı teknolojiler. Açıköğretim Uygulamaları ve Araştırmaları Dergisi, 3, 37-60.

Sarıtepeci, M., Durak, H. ve Seferoğlu, S.S. (2016). Öğretmenlerin öğretim teknolojileri alanında hizmet-içi eğitim gereksinimlerinin fatih projesi kapsamında incelenmesi. Turkish Journal of Computer and Mathematics Education, 7, 601-620. 
Smith, D. W., ve Kelley, P. (2007). A survey of assistive technology and teacher preparation programs for individuals with visual impairments. Journal of Visual Impairments \& Blindness, 101, 429-433.

Sola-Özgüç, C.,ve Cavkaytar, A. (2014). Teacher use of instructional technology in a special education school for students with intellectual disabilities: A case study. Turkish Online Journal of Qualitative Inquiry, 5, 51-65.

Swinth, Y., ve Case-Smith, J. (1993). Assistive technology in early intervention: Theory and practice. J. Case-Smith (Ed.), Occupational Therapy and Early Intervention içinde (s. 342-68). Boston: Butterworth Heinemann.

Sydeski, R. T. (2013). A study of special education teachers " knowledge of assistive technology for children with reading difficulties. Unpublished Doctoral Dissertation. Pittsburgh: Duquesne University.

Tekinarslan, E., ve Yıkmış, A. (2005). Özel eğitim kurumlarında çalışan öğretmenlerin teknoloji kullanımına yönelik görüşleri ve beklentileri. Abant İzzet Baysal Üniversitesi Sosyal Bilimler Enstitüsü Dergisi, 2, 211-220.

Todis, B. J. (1996). Tools for the task? Perspectives on assistive technology in education settings. Journal of Special Education Technology, 13, 49-61.

Van Netten J. J., Jannink, M. J., Hijmans, J. M., Geertzen, J. H. ve Postema, K. (2010). Use and usability of custom-made orthopedic shoes. Journal of Rehabilitation Research \& Development, $81,47-73$.

Vural, A. R., ve Ceylan V. K. (2014). Fatih projesi eğitimde teknoloji kullanım kursunun öğretmen görüşlerine göre değerlendirilmesi. INET-TR'1419. Türkiye'de Internet Konferansı, Yaşar Üniversitesi, İzmir. 
Wilcox, M. J., Guimond, A., Campbell, P. H., ve Moore, H. W. (2006). Provider perspectives on the use of assistive technology for infants and toddlers with disabilities. Topics in Early Childhood Special Education, 26, 33-49.

Wisconsin Assistive Technology Initiative. http://www.wati.org. Erişim Tarihi: 11.08.2018.

Yıldız, H., Sarıtepeci, M. ve Seferoğlu, S. S. (2013). FATİH Projesi kapsamında düzenlenen hizmet-içi eğitim etkinliklerinin öğretmenlerin mesleki gelişimine katkılarının ISTE öğretmen standartları açısından incelenmesi. Öğretmen Eğitiminde Yeni Eğilimler Uluslararast Sempozyumu'nda sunulan bildiri, Ankara.

Zhou, L.,Parker, A. T., Smith, D. W., ve Griffin-Shirley, N. (2011). Assistive technology for students with visual impairments: Challenges and needs in teachers' preparation programs and practice. Journal of Visual Impairment \& Blindness, 105, 197-210.

\section{Summary}

\section{Problem Statement}

Assistive technologies are defined as any means, service or method that is used to enable individuals with special needs to benefit from educational services, to live independently as individuals, and to improve their quality of life. It is important that the assistive technologies that are developed, as well as how often and how effectively the teachers use assistive technology classes. The effective use of assistive technologies is closely related to how much information and equipment the special education teachers have about assistive technologies. It seems that the published research that reveals the opinions of special education teachers about the use of assistive technologies in the summer of the national field seems rather limited.

Assistive technologies are designed to enable special needs individuals to learn various daily life skills (reading, writing, walking, running, running, eating, etc.) as well as being able 
to live independently as individuals in the society, as well as enjoying general education curricula can provide significant contributions. Therefore, it is considered that determining the factors that prevent special education teachers working in our country from using assistive technologies, providing support strategies that can be implemented by making necessary regulations and developing educational policies may be important. It is also thought that the lack of a published survey, which reveals the views of special education teachers on the use of assistive technologies in the summer of the national field, suggests that this work may make a significant contribution to the national literature.

Purpose of the Study: The purpose of this study is to determine at what level assistive technologies are utilized in the special education field, to identify the barriers to use of assistive technologies, and to support strategies based on opinions and thoughts of teachers working on this field.

\section{Method}

This research is a descriptive study in the screening model. Screening models which aim to describe a past or present situation as it exists. In this research, a survey developed by researcher Linda Chmiliar in 2007 was used as the data collection tool. In the survey, 13 questions were used to determine the extent to which the teachers were using the assistive technology and how often they were satisfied with the assistive technology, 12 to determine the factors that impeded the use of assistive technology, 12 support strategies for assistive technology There are also 10 rating questions to determine. Data were collected from 211 teachers, 111 male and 100 female. The data were transferred to the SPSS 17.0 package program for statistical processing and the frequency, percentage, mean and standard deviation values were reached.

\section{Findings and Discussions}


As a result of the analysis, firstly, $68.2 \%(\mathrm{n}=144)$ of the teachers participating in the research stated that they did not receive in-service training on assistive technology. In similar research, teachers have stated that they do not have adequate in-service training with assistive technology and therefore do not feel well enough to use assistive technology. Second, it was found that $40.8 \%(n=86)$ of the teachers were not satisfied with current knowledge and skills about assistive technology, 59.2\% $(\mathrm{n}=125)$ were moderately satisfied with current knowledge and skills about assistive technology, they were pleased. However, it is thought that this finding may be related to the level of available assistive technologies on the inventory list of official and private education institutions in Hakkâri province. Teachers participating in the research have the most discouraging factors in using assistive technology; the cost of tools and equipment, the complexity of tools and software, the lack of tools and equipment for the students at school, the lack of knowledge about assistive technology, and the lack of technical support for the maintenance of equipment in schools. Findings from this study support the findings of other studies in the literature. The teachers participating in the research have the most important support strategies regarding the use of assistive technologies; budget support, educational support, equipment support and access to the technical support required to use the equipment. The most important support strategies that teachers indicated in this study are similar to the findings of the research conducted by Chmiliar (2007). Budget support in the use of assistive technologies is shown among the most important support strategies in various surveys.

\section{Conclusions and Recommendations}

It can be assumed that this research has some limitations. First, this research is limited to the use of assistive technologies only by examining the views of special education teachers. In further research, the use of assistive technologies can be used to plan research into the views and ideas of family members (parents, siblings, etc.), health personnel or language and speech 
specialists. Further research may be undertaken to investigate the views of faculty members working at the university on the use of assistive technologies in special education. Thirdly, the questionnaire developed by Chmiliar (2007) as a means of data collection in this research was adapted and used in Turkish. Demographic information obtained from teachers in the questionnaire includes gender, age, current tasks in schools, whether they have received inservice training, etc. is limited to information. However, the questionnaire did not include demographic questions regarding the education levels of teachers (undergraduate, graduate, doctorate). Further research may be undertaken to investigate whether teachers' knowledge and skills related to assistive technology are related to the level of education they receive. 